\title{
Photocurable Polymeric Blends for Surgical Application
}

\author{
Teresa Cernadas ${ }^{1,+}{ }^{\circledR}$, Marta Santos ${ }^{1,+}$, Sónia P. Miguel ${ }^{2,3}{ }^{\circledR}$, Ilídio J. Correia ${ }^{1,2}$, \\ Patrícia Alves ${ }^{1}$ (D) and Paula Ferreira ${ }^{1, * \mathbb{D}}$ \\ 1 CIEPQPF, Department of Chemical Engineering, University of Coimbra, P-3030 790 Coimbra, Portugal; \\ mariac@eq.uc.pt (T.C.); marta.santos@uc.pt (M.S.); icorreia@fcsaude.ubi.pt (I.J.C.); palves@eq.uc.pt (P.A.) \\ 2 CICS-UBI, Health Sciences Research Center, University of Beira Interior, P-6200 506 Covilhã, Portugal; \\ spmiguel@ubi.pt \\ 3 CPIRN-IPG, Center of Potential and Innovation of Natural Resources, Polytechnic Institute of Guarda, \\ Av. Dr. Francisco de Sá Carneiro, 6300-559 Guarda, Portugal \\ * Correspondence: pferreira@eq.uc.pt \\ + These authors have made an equal contribution to this study.
}

Received: 22 October 2020; Accepted: 9 December 2020; Published: 12 December 2020

\begin{abstract}
The preparation of photocrosslinkable bioadhesives synthesized from oligomers of lactic acid and polycaprolactone (PCL), both functionalized with 2-isocyanoethyl acrylate (AOI), were studied. The obtained modified macromers of LA-AOI (mLA) and PCL-AOI ( $\mathrm{mCL}$ ) were chemically characterized by ${ }^{1} \mathrm{H}$ NMR and used to formulate polymeric blends with different mass proportions, 1:1, 1:2 and 2:1, respectively. Subsequently, the produced blends were crosslinked, considering two UV irradiation times: 30 and $120 \mathrm{~s}$. After their production, the thermal and mechanical properties of bioadhesives were assessed, where upon the rheology, gel content, hydrolytic degradation and dynamic contact angles were determined. Furthermore, the cytotoxic profile of bioadhesives was evaluated in contact with human dermal fibroblasts cells, whereas their antibacterial effect was studied monitoring Escherichia coli and S. aureus growth. Overall, flexible and resistant films were obtained, presenting promising features to be used as surgical bioadhesives.
\end{abstract}

Keywords: photocuring; polymeric blends; bioadhesive; biocompatibility; antibacterial activity

\section{Introduction}

At the end of the 20th century, a new trend emerged regarding the development of polymeric materials with numerous scientific studies reporting the use of polymeric blends as potential new materials for biomedical applications [1], and more specifically, on their use in the preparation of bioadhesives [2].

In fact, polymer blending is recognized as an inexpensive procedure that enables the adjustment of the materials' final properties, with a full set of tailored characteristics and improved specific features [1]. Generally, polymeric blends can be obtained by using one of two basic methods: blending melted or softened components, and/or by mixing solutions of components in the same solvent $[3,4]$.

Among the synthetic aliphatic polyesters, two of the most frequently used polymers in biomedical applications are poly(lactic acid) (PLA) and polycaprolactone diol (PCL), both approved by the Food and Drug Administration [5-7]. PLA is a highly versatile biodegradable and biocompatible polymer [8] with a glass transition temperature $\left(\mathrm{T}_{\mathrm{g}}\right)$ above room temperature, making it a hard and brittle material $[9,10]$. PCL is a biocompatible semi-crystalline linear polyester known for its high permeability, slow degradation rate and low $\mathrm{T}_{\mathrm{g}}$, rendering it resistant and tough [9]. In both cases, their structures present several aliphatic ester linkages susceptible to hydrolysis, not depending on the action of enzymes to undergo biodegradation and, therefore, precluding inflammatory responses [7]. Thus, the products of hydrolytic degradation can either be metabolized, through the inclusion in a 
cell's metabolic pathway, or eliminated by renal secretion [11]. In both cases, physical-mechanical properties and biodegradation behavior can be tailored by blending, copolymerization or by changing the macromolecular architecture [12].

The work developed herein comprises polymeric blends based on low molecular weight (oligomers) of caprolactone (CL) and lactic acid (LA) that were further characterized and tested as possible materials for biomedical application. Both CL and LA oligomers were functionalized with 2-isocyanatoethyl acrylate (AOI), a vinylic isocyanate monomer. The choice of the AOI was based on the inexistence of reported research of this compound in the preparation of bioadhesive materials.

Three different stoichiometric proportions of functionalized PCL/LA oligomers mixtures were prepared and once the photocrosslinker Irgacure ${ }^{\circledR} 2959$ (Ir2959) was added to the solutions [13], well-defined crosslinked networks were obtained after two distinct irradiation times (30 and $120 \mathrm{~s}$ ). Therefore, the chemical functionalization with $\mathrm{AOI}$ as the vinylic monomer allowed to obtain crosslinked films with curing times appropriate to surgical demands. The choice of Ir2959 as the photoinitiating agent was based on literature that reported this compound as biocompatible in several cell lines and under a broad range of tested concentrations [13].

The chemical and physical properties of photocrosslinked films were further characterized in order to demonstrate their suitability as UV-curable bioadhesives. Additionally, their biocompatibility as well as their antibacterial activity were assessed.

\section{Materials and Methods}

\subsection{Materials}

Polycaprolactone diol (PCL, Mn $\approx 530 \mathrm{~g} \cdot \mathrm{mol}^{-1}$ ) and Lactic Acid L(+) (LA, 80\%) were acquired from Sigma-Aldrich (Sintra, Portugal). Diethyl ether (99\%), 1,4-butanediol (99\%) and anhydrous calcium chloride (96\%) were purchased from ACROS organics. 2-hydroxy-1-[4-(2-hydroxyethoxy) phenyl]-2-methyl-1-propanone (Irgacure ${ }^{\circledR} 2959,97-99 \%$ ) and 2-isocyanatoethyl acrylate (AOI, >98\%)) were purchased from Ciba Specialty Chemicals (Groot-Bijgaarden, Belgium) and TCI (Zwijndrecht, Belgium), respectively. The deuterated chloroform used as solvent was obtained from Merck (Kenilworth, New Jersey, USA). No further purification was performed to any of these reagents. Fetal bovine serum (FBS) (free from any antibiotic) was obtained from Biochrom AG (Berlin, Germany). Normal Human Dermal Fibroblasts (NHDF) cells were purchased from PromoCell (Labclinics, S.A., Barcelona, Spain). 3-(4,5-Dimethylthiazol-2-yl)-2,5-diphenyltetrazolium bromide (MTT) was acquired from Alfa Aesar (Ward Hill, MA, USA). Amphotericin B, Dulbecco's modified Eagle's medium (DMEMF12) and Trypsin were obtained from Sigma-Aldrich (Sintra, Portugal). Staphylococcus aureus clinical isolate (S. aureus, ATCC 25923) and Escherichia coli DH5 $\alpha$ (E. coli, DH5a) were purchased from ATCC (Teddington, UK) and used as model organisms to evaluate the antimicrobial properties of the adhesives.

\subsection{Blending and Crosslinkg}

\subsubsection{Lactic Acid Oligomers Synthesis}

Oligomers based on lactic acid (oligLA) were synthesized through polycondensation reactions, under atmospheric pressure. The reaction of lactic acid with 1,4-butanediol, was performed in the stoichiometry of 6:1, respectively, in a round-bottom glass flask equipped with a water glass collector and placed in an oil bath at the temperature of $150{ }^{\circ} \mathrm{C}$. Constant nitrogen flow and magnetic stirring (Labox, LBX H03D, 3 L, Labbox Labware S.L., Spain) were maintained throughout the reaction time of $9 \mathrm{~h}$. 


\subsubsection{Modification of Prepolymers with AOI}

The modification of the oligLA and PCL was achieved by using AOI, a vinylic monomer, in two distinct reactions. The volume of AOI was determined to ensure total reaction of isocyanate groups. Diethyl ether (10 mL per $0.02 \mathrm{~mol}$ of oligomer) was used as solvent to dissolve AOI ( $0.04 \mathrm{~mol})$ in the previous mixtures. Both reactions proceeded in a round-bottom flask at $60^{\circ} \mathrm{C}$, for $24 \mathrm{~h}$, under reflux and magnetic stirring. The obtained functionalized macromers are further nominated as mLA (macromer of LA-AOI) and mCL (macromer of PCL-AOI).

\subsubsection{Preparation of Blends and Photocrosslinking}

The blends were obtained through homogeneously mixing $\mathrm{mLA}$ and $\mathrm{mCL}$, varying the mass proportions of each functionalized macromers. The obtained blends were designated as:

- LA1CL1: mLA and mCL in 1:1 ratio;

- LA2CL1: mLA and mCL in a 2:1 ratio;

- LA1CL2: mLA and $\mathrm{mCL}$ in a 1:2 ratio.

In order to prepare the blends, $4 \%$ (considering the carbon double bonds moles) of Irgacure ${ }^{\circledR} 2959$ (Ir2959) was added to the mixture and stirred under heat to obtain a homogeneous solution. Thereafter, these solutions were uniformly spread with a stainless-steel cylinder of $1 \mathrm{~mm}$ of thickness, and UV irradiated for $30 \mathrm{~s}$ and 2 min using a Multiband UV UVGL-48 with a wavelength of $356 \mathrm{~nm}$ from Mineral Light ${ }^{\circledR}$ Lamp (UVP LLC, Upland, CA, USA). Transparent, uniform and flexible films were obtained and further characterized.

\subsection{Characterization Techniques}

\subsubsection{Nuclear Magnetic Resonance (NMR) Spectroscopy}

mLA, mCL and the blends (LA1CL1, LA1CL2 and LA2CL1) chemical structure were confirmed by ${ }^{1} \mathrm{H}$ NMR analysis. Deuterated chloroform $\left(\mathrm{CDCl}_{3}\right)$ was selected as solvent and tetramethylsilane used as the internal reference. The spectra were obtained at room temperature in a Bruker Avance III $400 \mathrm{MHz}, 9.4$ Tesla Spectrometer (Brucker, Ettlingen, German).

\subsubsection{Rheological Studies}

Blends viscosity was determined using a controlled stress rheometer (Haake, model RS1, Karlsruhe, Germany) with a plate/plate system PP20Ti geometry (titanium for the rotating part and stainless steel for the stationary part) connected to a temperature control recirculation bath (Haake Phoenix II, Karlsruhe, Germany). The rheological behavior of the materials was measured at $25^{\circ} \mathrm{C}$ with a 0.2 $\mathrm{mm}$ GAP and the viscosities in function of the shear rate over time were attained. The power law parameters, fitted using the Ostwald-de Waele model, were obtained using the Haake RheoWin 4.20.005 software (Haake, vision, Karlsruhe, Germany).

\subsubsection{Gel Content}

Solvent extraction was used to determine the gel content of the obtained films to qualitatively infer about the crosslinking degree. Briefly, dried films $(20 \times 10 \times 1 \mathrm{~mm})$ were weighed $\left(W_{i}\right)$, then immersed in diethyl ether $(99 \%)$ sealed containers, under stirring and at room temperature, overnight. Films were then removed, dried and reweighed $\left(W_{f}\right)$. Three samples of each film were measured and results presented as mean and standard deviation. Gel content was determined according to Equation (1).

$$
\text { Gel content }(\%)=\left(\frac{W_{f}}{W_{i}}\right) \times 100
$$




\subsubsection{Hydrolytic Degradation}

Hydrolytic degradation of three dried samples of each prepared film, with dimensions of $20 \times 10 \times 1 \mathrm{~mm}$, were weighed $\left(W_{d, 0}\right)$. Then, they were immersed in Phosphate Buffer Saline solution (PBS, $0.01 \mathrm{M}, \mathrm{pH} 7.4$ ) and incubated at $37^{\circ} \mathrm{C}$ for six weeks. Films were removed over time ( 24 and $72 \mathrm{~h}$ and 1, 2, 3, 4, 5 and 6 weeks) from the PBS solution, washed with distilled water and dried under vacuum, at $37^{\circ} \mathrm{C}$, until constant weight $\left(W_{d, t}\right)$. The degradation degree was assessed from the determination of weight loss by using Equation (2).

$$
\text { Weight loss }(\%)=\frac{W_{d, 0}-W_{d, t}}{W_{d, 0}} \times 100
$$

\subsubsection{Dynamic Contact Angles Measurements}

A Dataphysics OCA-20 contact angle goniometer (DataPhysics Instruments, Filderstadt, Germany) was used to determine the dynamic contact angles of the films, using the sessile drop method. Briefly, $10 \mu \mathrm{L}$ droplet of deionized water was mechanically dispensed on the surface of the films and its progress across time was recorded with a CCD video camera (DataPhysics Instruments, Filderstadt, Germany). Water contact angles were calculated using the equipment software. The results obtained are the mean values of three independent measurements.

\subsubsection{Thermal Analysis}

Thermo gravimetric analysis (TGA) was performed for all materials (before and after crosslinking) in order to evaluate their thermal stability. A TGA equipment SDT Q500 from Thermal Analysis (TA) Instruments (New Castle, DE, USA) was used. Amounts of 5 to $10 \mathrm{mg}$ of each material were heated to $600{ }^{\circ} \mathrm{C}$ with a heating rate of $10^{\circ} \mathrm{C} / \mathrm{min}$, under nitrogen purge with a flow rate of $100 \mathrm{~mL} / \mathrm{min}$. Data processing and determination of the degradation temperatures were performed with the universal analysis 2000 software from TA Instruments.

\subsubsection{Cell Growth and Proliferation}

Cell adhesion and proliferation of the Normal Human Dermal Fibroblasts (NHDF) in contact with crosslinked polymeric films were assessed. To accomplish such purpose, the films were positioned into 96-well plates and sterilized for $1 \mathrm{~h}$ by UV irradiation. After that, cells were seeded at a density of $10 \times 10^{3}$ cells per well. Along different timepoints, cell growth in the presence of the films was monitored using an Olympus CKX41 inverted light microscope equipped with an Olympus SP-500 UZ digital camera (Olympus Life Science, Waltham, MA, USA). To accomplish that, each well containing cells seeded in contact with films were photographed (at magnification of 100X) aiming to characterize the cell morphology of human fibroblasts.

Furthermore, the cytotoxic profile of the films was evaluated by MTT assay, following the guidelines established in ISO 10993-5. In brief, at different timepoints, the culture medium of each well was replaced by $50 \mu \mathrm{L}$ of MTT ( $5 \mathrm{mg} / \mathrm{mL}$ PBS) $(n=5)$. After that, the plate was incubated for $4 \mathrm{~h}$, at $37^{\circ} \mathrm{C}$, in a $5 \% \mathrm{CO}_{2}$ atmosphere to promote the metabolic conversion of MTT. During this time of incubation, the yellow tetrazole salt is converted to purple formazan crystals by living cells and such process is proportional to the number of viable cells present in each well. Then, the insoluble formazan crystals produced were dissolved with $200 \mu \mathrm{L}$ of DMSO $(0.04 \mathrm{~N})$ for $30 \mathrm{~min}$. The absorbance at $570 \mathrm{~nm}$ was read in a microplate reader (Biorad $\times$ Mark microplate spectrophotometer). Cells cultured without materials were used as negative control $\left(\mathrm{K}^{-}\right)$, while cells cultured with $\mathrm{EtOH}(96 \%)$ were used as positive control $\left(\mathrm{K}^{+}\right)$. 


\subsubsection{Antimicrobial Activity}

The films antimicrobial properties were determined by using S. aureus and E.coli as Gram-positive and Gram-negative bacteria models, respectively. Initially, bacteria culture at a concentration of $1 \times 10^{8}$ $\mathrm{CFU} / \mathrm{mL}$ were dispensed onto agar plates $[14,15]$. Then, circular films $(n=3)$ were placed on the agar plate and incubated for $24 \mathrm{~h}$, at $37^{\circ} \mathrm{C}$. Afterwards, the inhibitory halo diameter induced by the films were photographed and measured using ImageJ software (Scion Corp., Frederick, MD, USA). In addition, the characterization of the bacterial colonization at films' surface was recorded by SEM.

To accomplish that, samples were initially fixed with $2.5 \%(v / v)$ glutaraldehyde for $4 \mathrm{~h}$. Then, they were washed three times with PBS and subsequently dehydrated with increasing concentrations of EtOH (70\%, 80\%, 90\% and 100\%) and freeze-dried for $3 \mathrm{~h}$. Finally, the samples were fixed onto aluminum stubs with Araldite glue and sputter-coated with gold using a Quorum Q150R ES sputter coater (Quorum Technologies Ltd., Laughton, East Sussex, UK). SEM images were finally acquired with different magnifications, using an acceleration voltage of $20 \mathrm{kV}$, in a Hitachi S-3400N Scanning Electron Microscope (Hitachi, Tokyo, Japan) [15,16].

\section{Results and Discussion}

\subsection{Synthesis}

The experimental synthesis procedures here reported allowed three different photocrosslinked materials to be obtained by blending the two macromers, $\mathrm{mCL}$ and $\mathrm{mLA}$, in different mass proportions $(1: 1,2: 1$ and $1: 2)$.

Initially, both PCL and oligLA were modified with a functional agent, AOI, to introduce photocrosslinkable sites in the polymers chain. This reaction occurred between the hydroxylic $(-\mathrm{OH})$ groups of the diol with the isocyanate groups of AOI (-NCO) resulting in urethane linkages (-NHCOO-). The experimental protocol was designed in accordance with the functional agent and the authors' prior research work $[2,17,18]$. All blends obtained presented an apparent viscosity which led to infer a good behavior for in situ application.

Crosslinking were performed using a percentage of $4 \%$ of the carbon double bonds moles with a well-known biocompatible photoinitiator (Ir2959). Different irradiation times were tested and after $30 \mathrm{~s}$ crosslinked networks were obtained. However, a second irradiation time of $2 \mathrm{~min}$ was also tested in order to determine potential differences in the materials properties. It was found that the films with the highest amount of mLA were more flexible, while those that contained the highest amount of $\mathrm{mCL}$ became more resistant. A typical reaction scheme is presented in Figure 1.

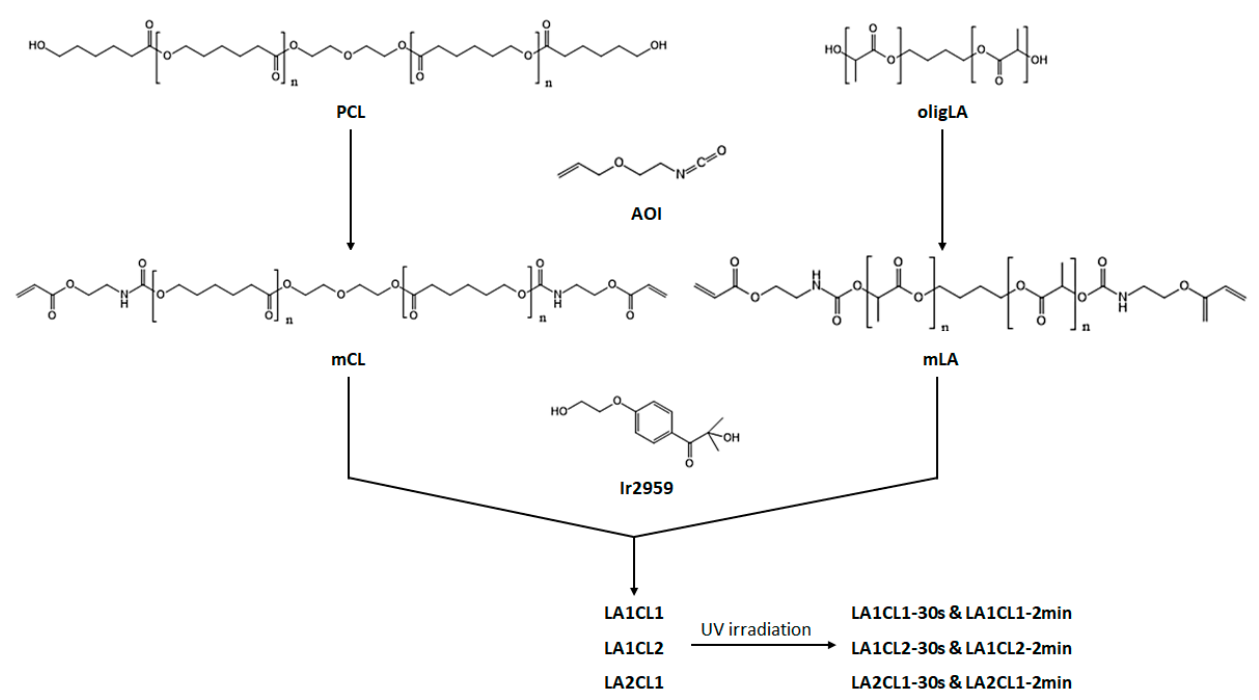

Figure 1. Schematic representation of the macromers synthesis and preparation of the three different blends. 


\section{2. ${ }^{1} \mathrm{H}$ NMR Analysis}

${ }^{1} \mathrm{H}$ NMR spectra of (1) AOI (2) PCL (3) mPA (4) oligLA (5) mLA are presented in Figure 2. The typical backbone peaks of PCL can be seen (3) at (f) 1.4, (g) 1.7, (h) 2.4 (j) 4.0 and (k) 4.2 ppm, which are assigned to the methylene proton $\left(-\mathrm{CH}_{2}\right)$. These peaks are also present in the MPA (4) spectra, except the terminal methylene protons $\left(-\mathrm{CH}_{2} \mathrm{OH}\right)$ at (i) $3.6 \mathrm{ppm}[17,19]$, due to the reaction of the $-\mathrm{OH}$ group with the urethane group from $\mathrm{AOI}[6]$ and, therefore, a new peak (1) around $3.5 \mathrm{ppm}$ is present, which is assigned to the urethane groups $\left(-\mathrm{NHCH}_{2}-\right)[2,6,19]$. The mLA (5) spectra follows the same interpretation, presenting the typical oligLA peaks at (r) $5.2 \mathrm{ppm}$ from methine proton -O- $\mathrm{CH}\left(\mathrm{CH}_{3}\right)-\mathrm{C}(\mathrm{O})-\mathrm{O}-$, (n) $1.4 \mathrm{ppm}$ from the methyl group - $\mathrm{CH}_{3}$ adjacent to the methine proton previously mentioned and (o) 1.5 and (q) $4.3 \mathrm{ppm}$ assigned to the methylene proton (- $\left.\mathrm{CH}_{2}\right)$ in the oligLA backbone [2,6,19], along with the presence of two new signals at (l) 3.5 and (m) $3.6 \mathrm{ppm}$ which were assigned to the urethane groups (-NH- $\mathrm{CH}_{2}$ - and $-\mathrm{NH}-\mathrm{C}=\mathrm{O}$ protons), respectively $[6,18,19]$, resulting from the reaction of the oligLA hydroxyl groups with the AOI urethane groups. Moreover, in both mLA (5) and mPA (4) spectra, the three resonance peaks are present at (c) 5.9, (e) 6.2 and (d) 6.5ppm, assigned to the olefinic protons of AOI, confirming the success of the synthesis.

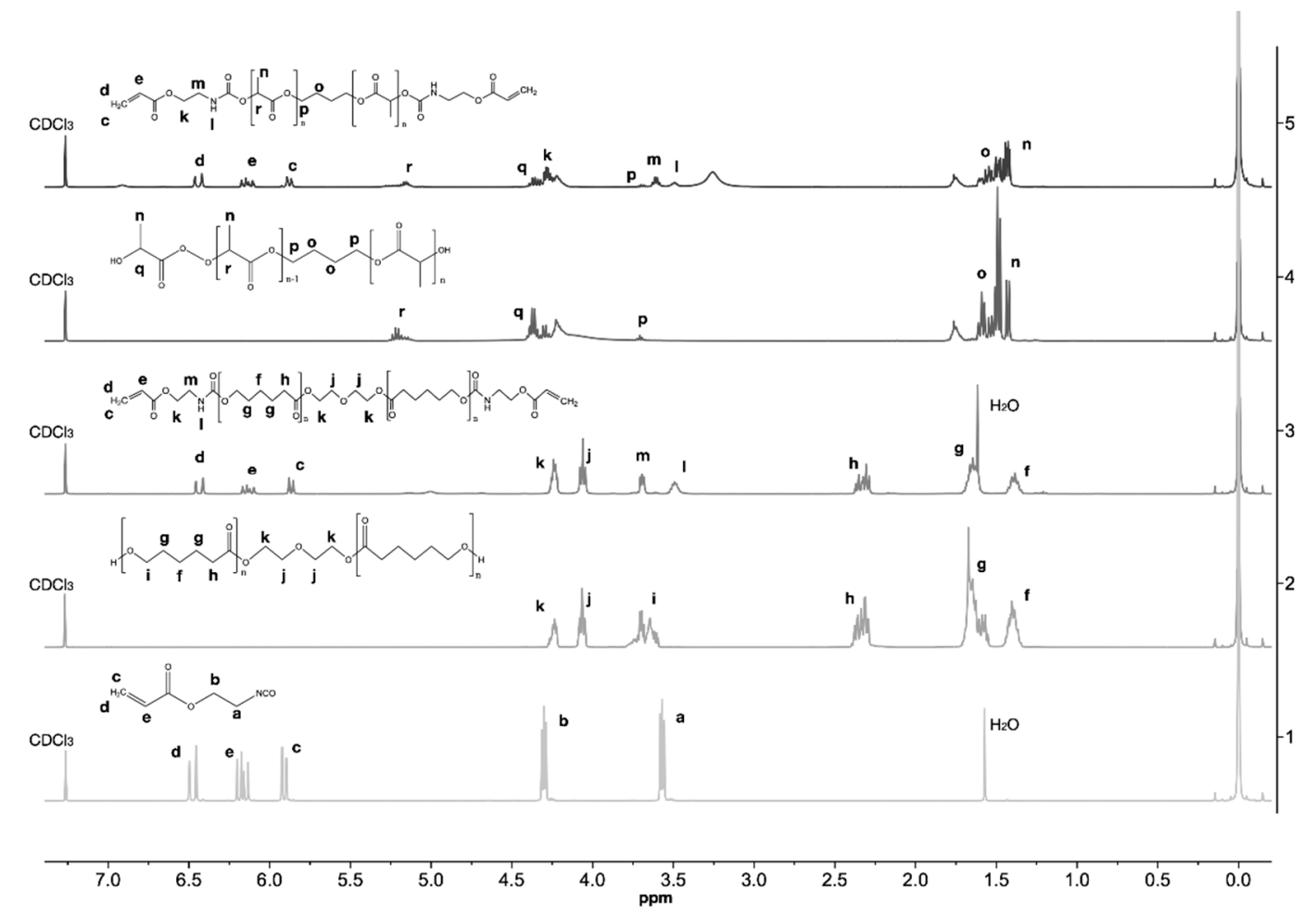

Figure 2. ${ }^{1} \mathrm{H}$ NMR spectra of (1) 2-isocyanoethyl acrylate (AOI) (2) polycaprolactone (PCL) (3) mPA (4) oligomers based on lactic acid (oligLA) (5) mLA in deuterated chloroform $\left(\mathrm{CDCl}_{3}\right.$ ) at $400 \mathrm{MHz}$.

\subsection{Rheological Studies}

Rheological studies were carried out in order to establish the relation between viscosity and shear rate (Figure 3). This analysis was performed considering the intended conditions for materials application (at room temperature).

Figure 3 shows the Newtonian behavior of the different blends-the viscosities are constant with the increase in the shear rate, meaning that the viscosity will remain constant no matter how fast they are forced to flow through any channel.

The similarity in flow behavior between the materials indicates that there are slight changes in their molecular structures. Additionally, all blends have relatively low viscosities, with values between 0.7 and 1 Pa.s, with LA2CL1 being the one with the lowest shear viscosity value. The results 
herein obtained are in agreement with the values previously reported in literature, including the tests performed on commercial bioadhesives [20,21].

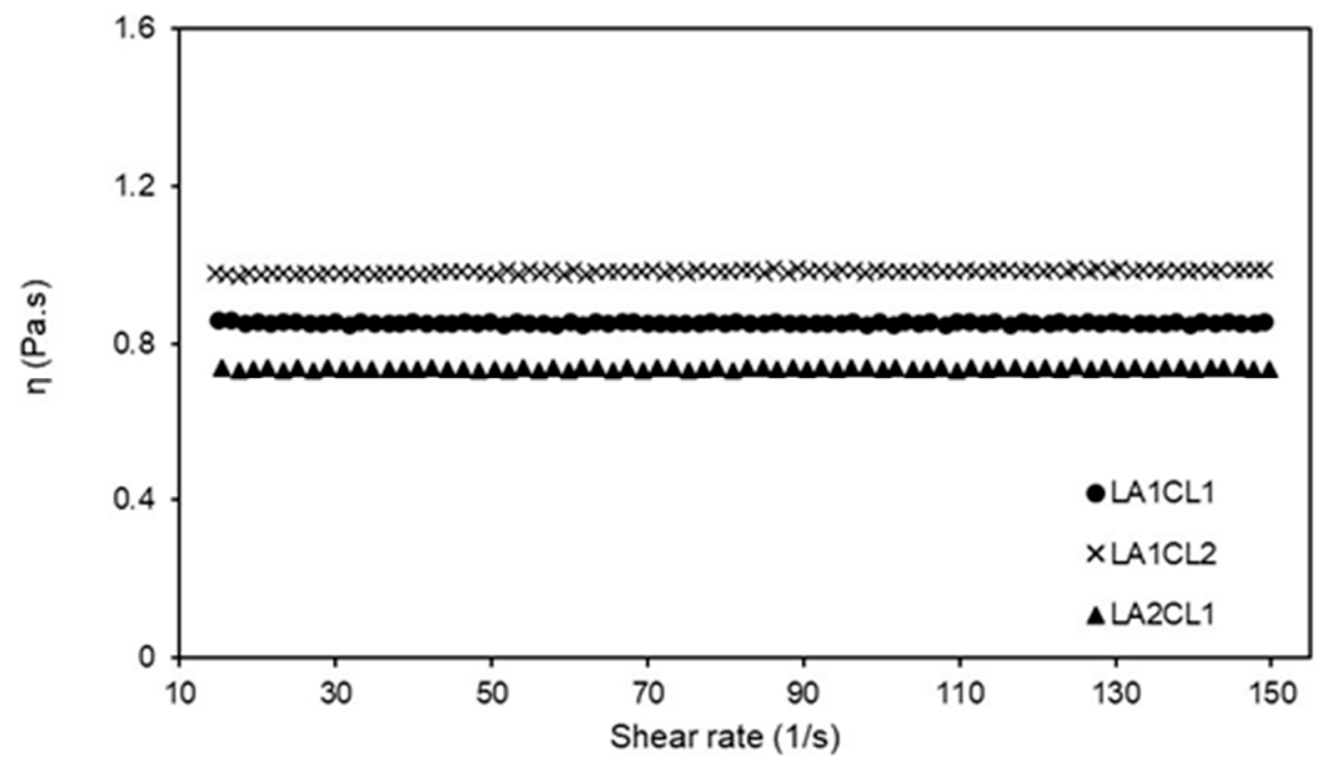

Figure 3. Viscosity of the three blends as function of shear rate, at constant temperature $\left(25^{\circ} \mathrm{C}\right)$.

Considering the application as surgical adhesives, the prepared blends must be easy to apply and adapt to the injured tissue. Therefore, the low viscosity (and a Newtonian profile) of these materials will allow them to flow and spread when acted upon by gravity or some other type of force, facilitating its application by a variety of methods.

\subsection{Dynamic Contact Angles}

Figure 4 shows the registered dynamic water contact angle results for the different blends after $30 \mathrm{~s}$ or $2 \mathrm{~min}$ of crosslinking reaction time. The results revealed that all WCA started between $75^{\circ}$ and $85^{\circ}$, showing a slightly hydrophobic behavior of all blends. Furthermore, the crosslinking time did not influence the water affinity of the blends, since no significant differences in the water spreading could be registered between the different crosslinking reaction times. However, some differences can be noticed concerning the composition of the blends. The evidence of $\mathrm{mCL}$ and mLA amount in the blends composition can be perceived from the obtained results. The adhesives with higher amount of $\mathrm{mCL}$ showed to have a less hydrophilic surface, with a final WCA of around $43^{\circ}$, due to PCL's strong hydrophobic nature [20]. On the other hand, the adhesives with higher amount of mLA (LA2CL1) presented lower WCA (around $20^{\circ}$ ) due to the presence of the hydrophilic OH groups from LA [2], with the tendency to decrease, while the adhesives LA1CL1 and LA1CL2 presented a stable WCA of around $40^{\circ}$ and $35^{\circ}$, respectively, after $35 \mathrm{~s}$. Therefore, the presence of a higher amount of mLA influences the biological response of these materials.

\subsection{Gel Content}

The analysis of the gel content was performed to assess the crosslinking degree of the films. Results of $100 \%$ gel content represent a complete crosslinking in which $\mathrm{C}=\mathrm{C}$ were fully converted.

The crosslinking time is a determining aspect in the crosslinking degree results. Due to that, in this study, the influence of two different UV exposure times on the different prepared adhesive films was evaluated (Table 1). 


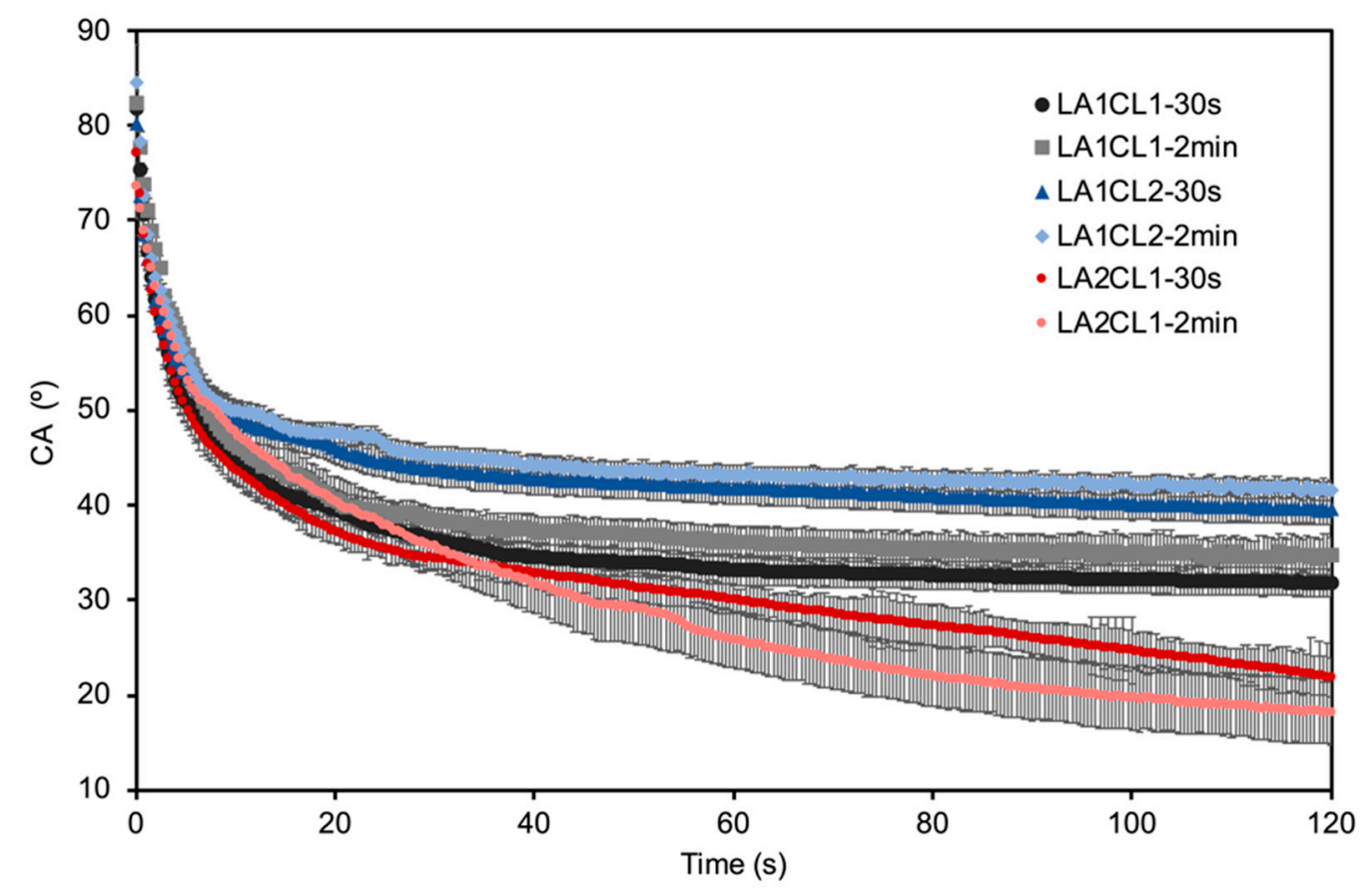

Figure 4. Dynamic water contact angles profiles obtained for the different adhesive formulations.

Table 1. UV exposure times (s) and corresponding gel content for each crosslinked adhesive.

\begin{tabular}{ccc}
\hline Adhesive Blends & UV Irradiation Time (s) & Gel Content (\%) \\
\hline \multirow{2}{*}{ LA1CL1 } & 30 & $64.2 \pm 3.40$ \\
& 120 & $77.6 \pm 0.27$ \\
\cline { 2 - 3 } LA1CL2 & 30 & $68.9 \pm 0.45$ \\
& 120 & $79.5 \pm 0.31$ \\
\cline { 2 - 3 } LA2CL1 & 30 & $47.8 \pm 1.78$ \\
& 120 & $68.1 \pm 0.14$ \\
\hline
\end{tabular}

As would be expected, Table 1 shows that higher UV exposure periods result in higher percentages of gel content as well as in stiffer and more compact materials.

Additionally, it was possible to verify that increasing $\mathrm{mCL}$ content in the polymeric blend (LA1CL2) led to an increase in gel content and, therefore, an enhanced crosslinking degree. This higher crosslinking and stability of the $\mathrm{mCL}$ urethane matrix linkages is due to its more pronounced rigidity and to the stronger establishment of hydrogen bonds between urethanes $\mathrm{NH}$ and $\mathrm{CO} / \mathrm{C}=\mathrm{O}$ groups in the hard segments of the mCL backbone in the urethane.

\subsection{Hydrolytic Degradation}

The biodegradability and capacity of the surgical adhesives being absorbed by the organism is an important property when they are aimed to be used in internal applications [6,21]. To assess the hydrolytic degradation of the photocrosslinked materials, three samples of each adhesive were placed in PBS (pH 7.4) and incubated at $37^{\circ} \mathrm{C}$, to replicate physiological conditions. The assay was carried out for 5 weeks, and the weight loss was calculated over time, which is presented in Figure 5. 


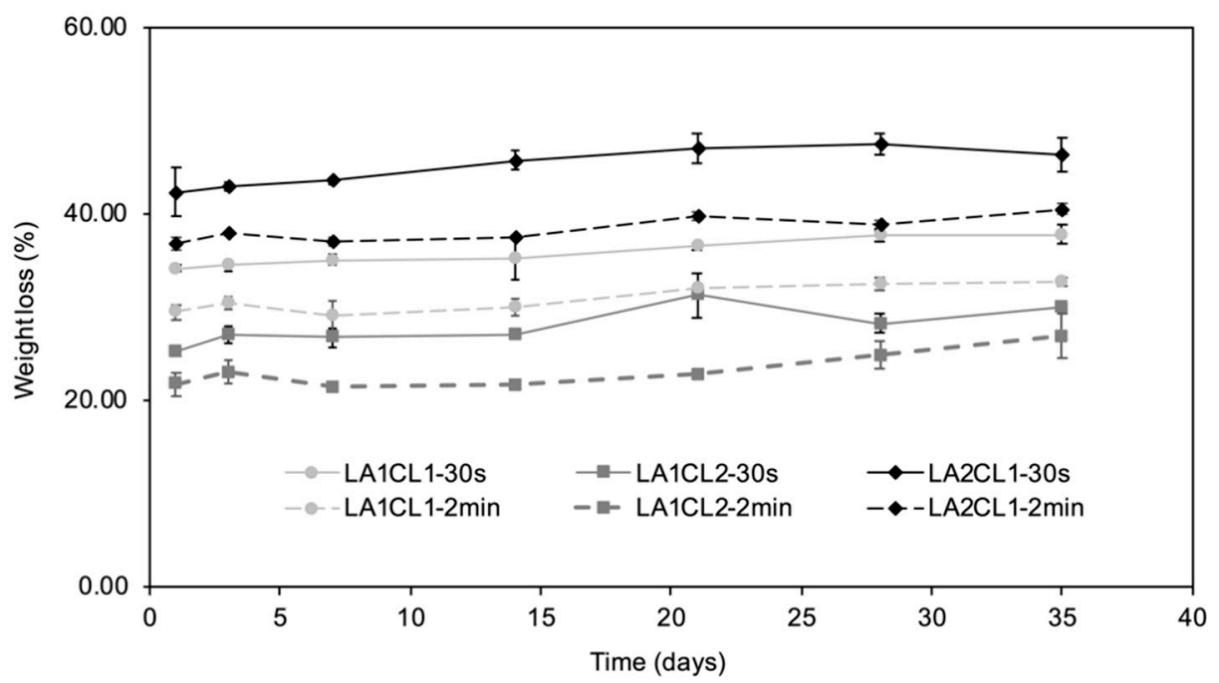

Figure 5. Weight loss (\%) of the produced adhesives over 5 weeks.

All adhesives showed greater weight loss in the first $24 \mathrm{~h}$ of testing. This result can be explained by the release of residual solvent (diethyl ether) still present in the matrix, as well as unreacted molecules from the UV-curing reaction $[2,6]$.

The hydrophobicity and stability of PCL makes the MCL macromer more resistant and stable than mLA macromer, whose ester bonds are more susceptible to hydrolytic degradation [21,22]. These results are also related to the WCA (Section 3.4), which showed that adhesives with a higher amount of mLA presented lower WCA and, consequently, a more hydrophilic surface. As can be observed in Figure 5, the increase in the proportion of mLA in the adhesives resulted in higher weight loss percentages. LA2CL1 adhesive presented the higher degradation value: $46.39 \% \pm 1.75 \%$ for $30 \mathrm{~s}$ irradiation. On the contrary, LA1CL2-2min presented the lowest weight loss degree $(26.82 \% \pm 2.40 \%)$. All tested adhesives showed higher percentages of degradation for shorter irradiation times, due to lower degree of crosslinking.

Although all the materials have potential to be used as surgical adhesives, the LA1CL1 and LA1CL2 formulations were the ones that presented the most satisfactory mass loss results for both photocrosslinking times (30 s and $2 \mathrm{~min}$ ).

\subsection{Thermal Properties}

Thermal stabilities of initial blended macromers as well as their crosslinked films obtained with $30 \mathrm{~s}$ or 2 min UV irradiation are presented in Figure 6. Furthermore, a summary of the main registered thermal events is presented in Table 2.

As presented in Figure 6A, $\mathrm{A}^{\prime}$, thermal degradation of LA1CL1 presents an intermediate profile between de LA1CL2 and LA2CL1. Moreover, all blends present a three stage degradation profile. The first one is related with the degradation of the urethane bonds and subsequent formation of carbon dioxide and monoxide, amines and aldehydes [23]. The second step is ascribed to the degradation of ester bonds in the urethanes' soft segments and occurred at a higher temperature value for the blend with the larger $\mathrm{mCL}$ ratio (L1CL2). This increase in thermal stability is justified by the urethane hard segments in the polymeric backbone, which allow the urethanes' $\mathrm{NH}$ and $\mathrm{CO} / \mathrm{C}=\mathrm{O}$ groups to establish hydrogen bonds [24]. The more rigid structure of PCL and stronger hydrogen bonding contribute to the increased thermal stability of the system. Finally, the last degradation step is attributed to the decomposition of $\mathrm{C}=\mathrm{O}, \mathrm{C}=\mathrm{C}, \mathrm{C}-\mathrm{O}$ and $\mathrm{C}-\mathrm{H}$ bonds which present higher energies and, therefore, require a larger temperature value to degrade [23]. 

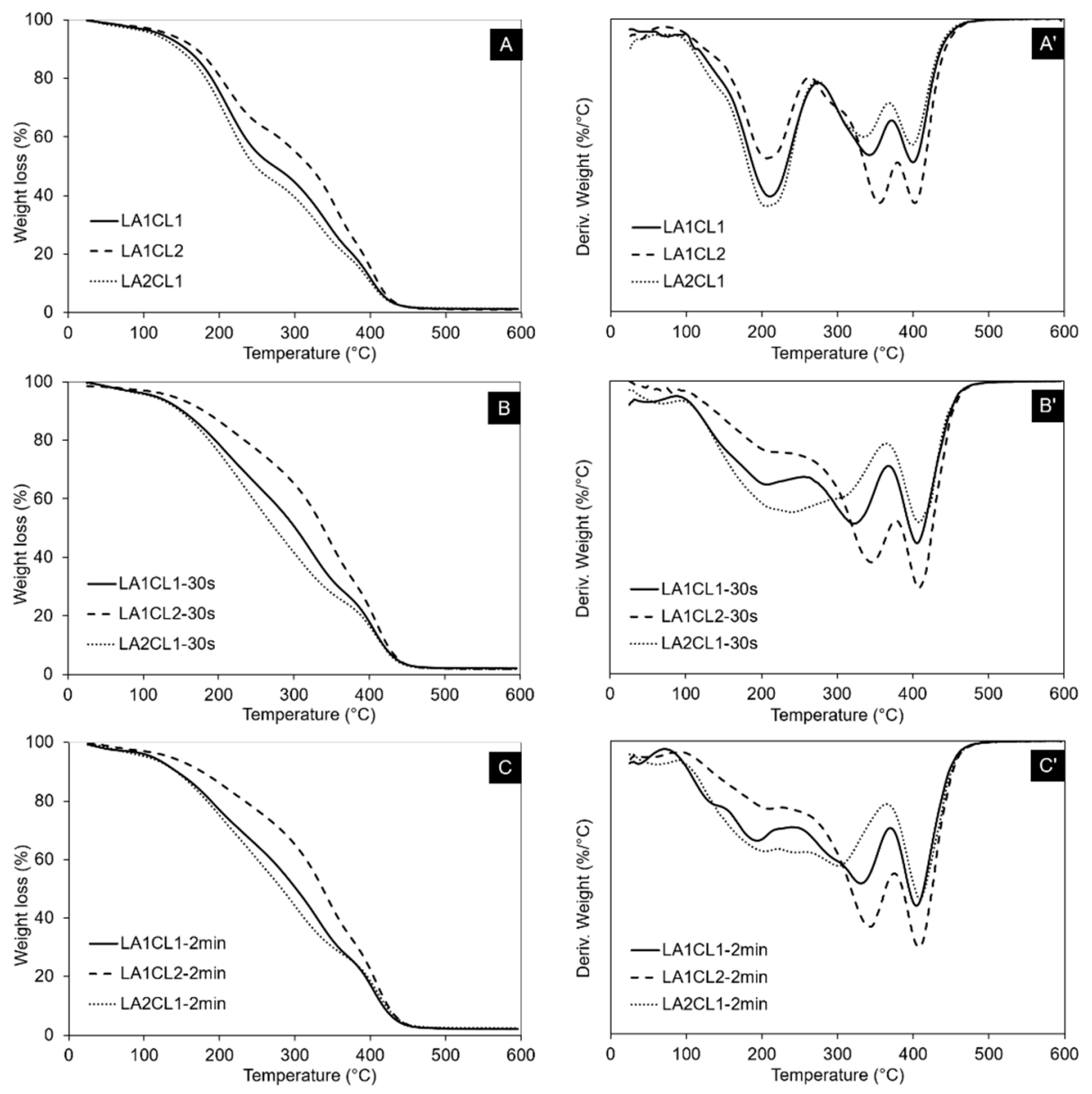

Figure 6. Thermograms registered for the blended macromers (A) and their crosslinking products obtained with $30 \mathrm{~s}$ (B) and $2 \mathrm{~min}(\mathbf{C})$ of UV irradiation. Figures $\mathbf{A}^{\prime}, \mathbf{B}^{\prime}$ and $\mathbf{C}^{\prime}$ show the correspondent derivative thermogravimetry (DTG) thermograms.

Table 2. Summary of the main registered thermal events in thermo gravimetric analysis (TGA). Tmax represents the temperature value corresponding to the highest degradation rate at each degradation stage and $\Delta W$ represents the correspondent weight loss (\%). T50 represents the temperature at which samples' weight decreased to $50 \%$ of the initial one.

\begin{tabular}{|c|c|c|c|c|c|c|c|c|}
\hline & \multicolumn{2}{|c|}{ 1st Stage } & \multicolumn{2}{|c|}{ 2nd Stage } & \multicolumn{2}{|c|}{ 3rd Stage } & \multirow[b]{2}{*}{$\begin{array}{l}\text { T50 wt \% } \\
\left({ }^{\circ} \mathrm{C}\right)\end{array}$} & \multirow[b]{2}{*}{$\begin{array}{c}\text { Residue at } 500{ }^{\circ} \mathrm{C} \\
\text { (wt \%) }\end{array}$} \\
\hline & $\begin{array}{c}\operatorname{Tmax1} \\
\left({ }^{\circ} \mathrm{C}\right)\end{array}$ & $\begin{array}{c}\Delta W 1 \\
(w t \%)\end{array}$ & $\begin{array}{c}\operatorname{Tmax} 2 \\
\left({ }^{\circ} \mathrm{C}\right)\end{array}$ & $\begin{array}{c}\Delta W 2 \\
(w t \%)\end{array}$ & $\underset{\left({ }^{\circ} \mathrm{C}\right)}{\operatorname{Tmax} 3}$ & $\begin{array}{c}\Delta W 3 \\
(\mathrm{wt} \%)\end{array}$ & & \\
\hline LA1CL1 & 209.32 & 28.87 & 347.00 & 70.82 & 404.91 & 90.08 & 272.69 & 1.34 \\
\hline LA1CL2 & 207.41 & 21.92 & 357.99 & 66.00 & 405.57 & 87.40 & 319.50 & 1.17 \\
\hline LA2CL1 & 206.91 & 31.83 & 333.83 & 70.65 & 400.09 & 89.53 & 247.79 & 1.55 \\
\hline LA1CL1-30s & 206.30 & 23.00 & 320.66 & 57.02 & 406.49 & 85.00 & 301.83 & 2.21 \\
\hline LA1CL2-30s & 216.83 & 16.52 & 348.44 & 54.78 & 410.88 & 83.30 & 338.78 & 2.02 \\
\hline LA2CL1-30s & 213.18 & 20.51 & 312.46 & 62.36 & 405.70 & 85.58 & 274.41 & 1.99 \\
\hline LA1CL1-2min & 194.07 & 21.45 & 330.04 & 60.39 & 404.24 & 84.65 & 301.66 & 2.29 \\
\hline LA1CL2-2min & 209.76 & 15.67 & 342.45 & 52.75 & 407.79 & 81.94 & 337.04 & 2.23 \\
\hline LA2CL1-2min & 203.30 & 25.90 & 300.66 & 56.05 & 408.31 & 84.93 & 282.24 & 2.56 \\
\hline
\end{tabular}

The increased thermal stability with $\mathrm{mCL}$ is also visible in the crosslinked blends. For both UV irradiation times, it was verified that thermal degradation occurs at higher values of temperature, when compared with the blends with lower mCL ratio. Moreover, all crosslinked materials present higher thermal stability than the corresponding original blend. As can be perceived in Figure $6 \mathrm{~B}^{\prime}, \mathrm{C}^{\prime}$, the areas under the curves of the first degradation step are significantly lower than the ones of the 
original blends (Figure $6 \mathrm{~A}^{\prime}$ ), meaning that the crosslinked structure of the polymeric blends contributes to increasing the stability of the polymeric structural bonds.

Considering the temperature at which samples' weight decreased into $50 \%$ of the initial one $\left(T_{50} \mathrm{wt} \%\right)$, similar findings were observed. Herein, the blends containing a higher $\mathrm{mCL}$ ratio are more thermally stable, presenting degradation temperatures between 30 and $60^{\circ} \mathrm{C}$ above the other formulations.

Moreover, at $500^{\circ} \mathrm{C}$, all the materials were almost fully degraded with a medium residue value of $1.35 \%$ for the initial blends and of $2.23 \%$ for the crosslinked ones. Additionally, no significant differences were observed in this parameter for the two UV irradiation periods tested.

\subsection{Characterization of the Crosslinked Polymeric Blends' Biological Properties}

\subsubsection{Cell Growth and Proliferation}

The NHDF cells were seeded in contact with films and then the optical microscopes images were acquired after 1, 3 and 7 days of incubation, as can be observed in Figure 7.

Morphology of the human fibroblast cells did not show any variation after being incubated with 2 min UV irradiated films (LA1CL1-2min, LA1CL2-2min and LA2CL1-2min) for at least 7 days. However, the cells seeded in contact with films crosslinked during $30 \mathrm{~s}$ displayed a morphology similar to the ones of $\mathrm{K}^{+}$(dead cells treated with ethanol) revealing that these specific films (LA1CL1-30s, LA1CL2-30s and LA2CL1-30s) induced a cytotoxic effect on the tested cells.

Furthermore, the cell viability was also quantified through the MTT assay at the same timepoints. Through this assay, it was noticed that the absorbance of the samples is proportional to the amount of the purple formazan crystals produced by the viable cells in each well $[15,20]$. The results obtained (Figure 8) clearly demonstrate that the UV irradiation times influenced the biocompatible character of photocrosslinked films. Therefore, $30 \mathrm{~s}$ irradiation time can be insufficient to promote an effective crosslinking between $\mathrm{mLA}$ and $\mathrm{mCL}$, thus promoting the release of the unreacted molecules and residual solvent (diethyl ether) which induce a cytotoxic effect for fibroblasts cells. Such findings are in agreement with the results obtained in the determination of gel content and weight loss (Sections 3.5 and 3.6).

Considering these results, the films photocured for 2 min exhibited an improved biological profile to be used as bioadhesives. The blending between mLA and $\mathrm{mCL}$ allowed flexible and stable films with a swelling and hydrophilicity profile to be obtained that promote the cell adhesion and proliferation. These are quite important results, since exposure time is critical when working with UV irradiation. Extended UV irradiation periods of time may result in cell mutation or even death. However, the results herein presented prove that a maximum of $2 \mathrm{~min}$ of UV irradiation does not have a negative impact on cell viability. The same fact has been reported by Sabnis et al., who showed that exposure of muscle cells in the presence of Irgacure ${ }^{\circledR} 2959$ to 1, 3 and 5 min of UV irradiation did not result in any statistically significant decrease in cell survival rates comparing to control cells [25].

\subsubsection{Antimicrobial Activity}

When a surgical adhesive is aimed to improve the wound closure process, it is extremely important that the material avoid the occurrence of a severe and devasting skin infection [26]. In this work, the antimicrobial profile of the films was assessed against E. coli (Gram-negative bacterium) and S. aureus (Gram-positive bacterium). The films were placed in contact with bacterial culture, and the diameters of the inhibitory halos were determined after $24 \mathrm{~h}$ of incubation. In addition, the bacterial colonization on the surface of the films was also characterized by SEM technique.

The results presented in Figure 9 clearly evidenced that all formulations displayed a high antimicrobial effect against E. coli growth, exhibiting an inhibition area higher than $70 \%$, with the exception of the LA1CL2-30s formulation that displayed a lower inhibition area with a value of $52.63 \% \pm 1.68 \%$. 


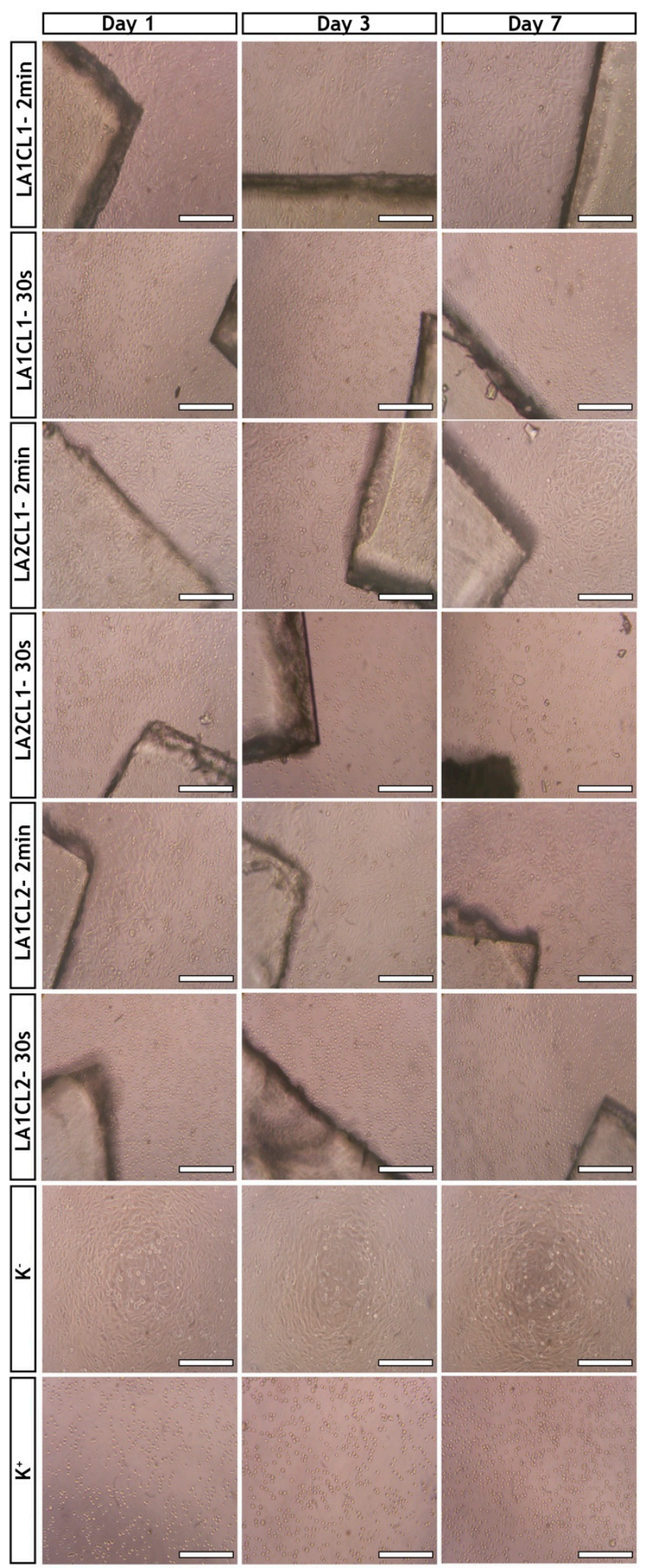

Figure 7. Optical microscopic images of NHDF cells cultured in the presence of produced films (LA1CL1, LA1CL2 and LA2CL1 photocrosslinked for $2 \mathrm{~min}$ and $30 \mathrm{~s}$ ) for 1, 3 and 7 days; $\mathrm{K}^{-}$(negative control); $\mathrm{K}^{+}$(positive control). Scale bar represents $200 \mu \mathrm{m}$. Magnification 100×; resolution $1.2 \mu \mathrm{m}$. 


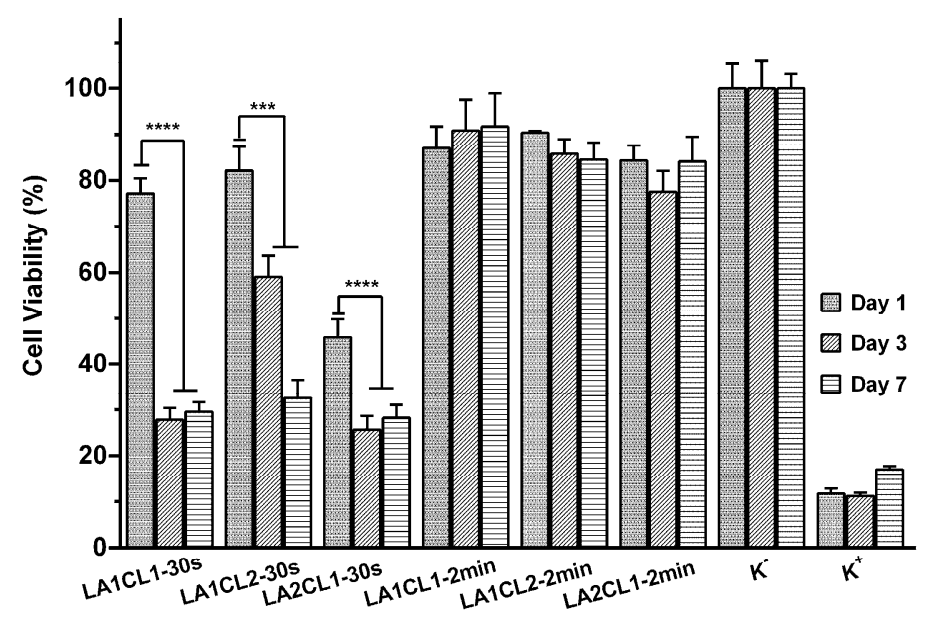

Figure 8. Characterization of cell viability through the MTT assay after 1, 3 and 7 days of incubation. $\mathrm{K}-$ (negative control); $\mathrm{K}+$ (positive control). Data are presented as the mean \pm standard deviation, $n=5$, ${ }^{* * *} p<0.001,{ }^{* * * *} p<0.0001$.

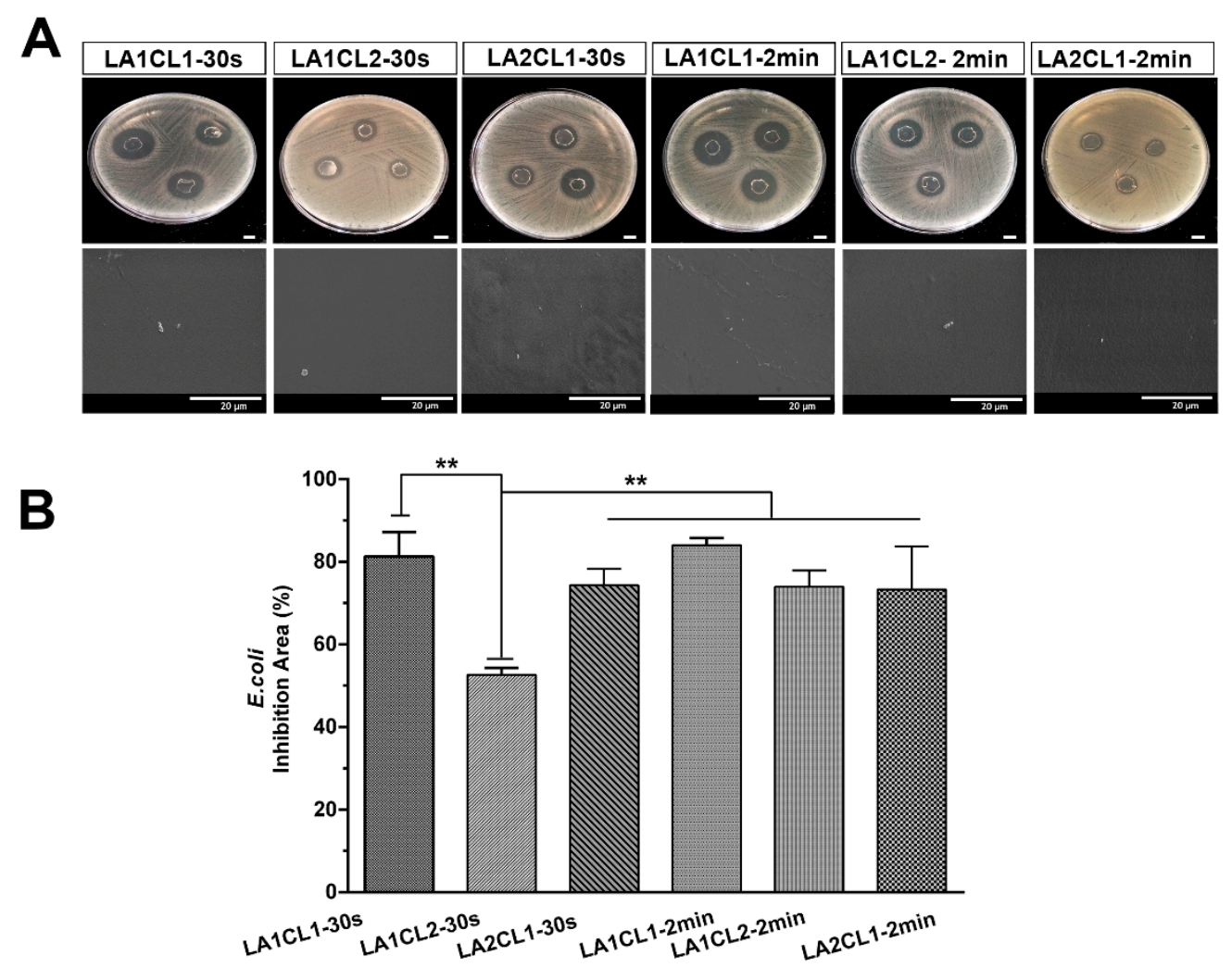

Figure 9. Assessment of antimicrobial profile of the photocrosslinked films against E. coli. (A) Macroscopic images of the inhibitory halos. (B) Relative value of the inhibition area presented by the films. Data are presented as the mean \pm standard deviation, $n=3$.

Similar results were also observed when the adhesives were incubated with S. aureus (Figure 10), where higher inhibition area values $(>75 \%)$ were noticed for all adhesives, with lower inhibition area value $(63.95 \% \pm 3.77 \%)$ exhibited by LA1CL2-30s formulation. Such results were expected since this formulation presents a higher amount of $\mathrm{mCL}$ and PCL is known by its hydrophobicity and non-antimicrobial activity $[27,28]$. 


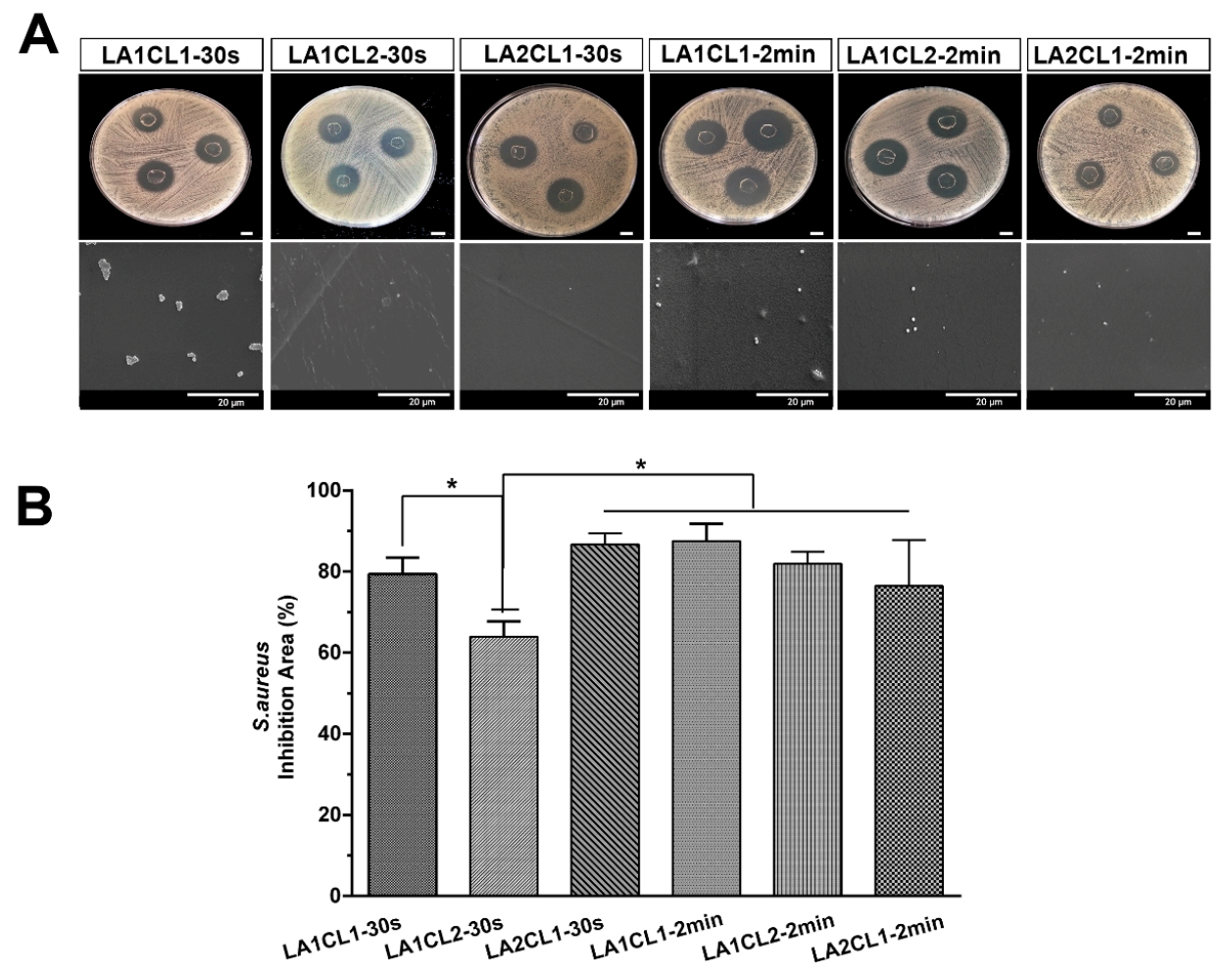

Figure 10. Assessment of antimicrobial profile of the photocrosslinked films against S. aureus. (A) Macroscopic images of the inhibitory halos. (B) Relative value of the inhibition area presented by the films. Data are presented as the mean \pm standard deviation, $n=3,{ }^{*} p<0.05$.

According to the SEM images, the bacterial colonization of E. coli and S. aureus were effectively suppressed at the surface of all prepared films. In general, all formulations presented an excellent antimicrobial effect, which can be correlated with the hydrophilic character of the adhesives due to the presence of mLA. According to the literature, the hydrophilic surfaces (WCA $>40^{\circ}$ ) impair the bacterial growth, since the adsorption of the water molecules on these surfaces is favorable, promoting repulsive forces of proteins, which reduces the protein adsorption [29]. Indeed, Yuan et al. verified that a superhydrophilic substrate presented a limited bacterial binding, due to the repulsive interaction between E. coli and the substrate [30]. Furthermore, it is also described that the lactic acid oligomers are able to disrupt the cytoplasmic membranes, the content and activity of bacterial proteins, leading to bacterial death $[31,32]$.

\section{Conclusions}

In the present work, mCL and mLA blends were prepared with different proportions and UV cured for $30 \mathrm{~s}$ and $2 \mathrm{~min}$. Generally, the obtained polymeric blends presented a suitable viscosity to be used as bioadhesives while the crosslinked films showed to be flexible yet resistant. However, different proportions led to distinct behavior of the films. LA2CL1 presented a less crosslinked matrix, a more hydrophilic surface and higher degradation profile. On the other side, the UV irradiation time influenced the biocompatible character of the films. In general, the films photocrosslinked for $2 \mathrm{~min}$ (LA1CL1-2min, LA1CL2-2min and LA2CL1-2min) displayed a better biological performance, since the human fibroblasts remain viable and proliferated for 7 days, when seeded in contact with these materials. Moreover, the antimicrobial assays revealed that all photocured films exhibited an excellent antimicrobial effect against E.coli and S. aureus growth, with the exception of LA1CL2-30s formulation that presented the lower inhibition area values $(<70 \%)$.

Considering all obtained data, the films, especially those crosslinked under UV irradiation for $2 \mathrm{~min}$, presented the most auspicious properties to be applied as bioadhesives. 
Author Contributions: T.C., P.A. and P.F. conceived and planned the experiments. M.S. contributed to sample preparation and carried out the experiments. S.P.M. carried out the biocompatibility experiments. T.C., M.S., S.P.M., I.J.C., P.A. and P.F. contributed to the interpretation of the results. T.C. and M.S. took the lead in writing the manuscript. P.F. and P.A. were responsible for the research supervision. P.F. was the project administrator. All authors have read and agreed to the published version of the manuscript.

Funding: This research was funded by the Portuguese Foundation for Science and Technology through the project FCT Researcher-grant number IF/01432/2015; project ZAPGO—grant number PTDC/NAN-MAT/28989/2017) and project INEYE_-grant number PTDC/EMD-EMD/31462/2017. The authors from CIEPQPF were supported by FCT—Fundação para a Ciência e a Tecnologia (Portuguese Foundation for Science and Technology) UIDB/00102/2020.

Acknowledgments: The authors would like to thank the UC-NMR facility for the NMR data collection, which is supported in part by FEDER - European Regional Development Fund through the COMPETE Programme (Operational Programme for Competitiveness) and by National Funds through FCT through grants RECI/QEQ-QFI/0168/2012, CENTRO-07-CT62-FEDER-002012, and also through support to Rede Nacional de Ressonância Magnética Nuclear (RNRMN) and to Coimbra Chemistry Centre through grant UID/QUI/00313/2019.

Conflicts of Interest: The authors declare no conflict of interest. The funders had no role in the design of the study; in the collection, analyses, or interpretation of data; in the writing of the manuscript, or in the decision to publish the results.

\section{References}

1. Doulabi, A.H.; Mequanint, K.; Mohammadi, H. Blends and nanocomposite biomaterials for articular cartilage tissue engineering. Materials 2014, 7, 5327-5355. [CrossRef] [PubMed]

2. Cernadas, T.M.; Gonçalves, F.A.M.M.; Alves, P.; Miguel, S.P.; Cabral, C.; Correia, I.J.; Ferreira, P. Preparation of biodegradable functionalized polyesters aimed to be used as surgical adhesives. Eur. Polym. J. 2019, 117, 442-454. [CrossRef]

3. Wang, Y.; Zhang, L. Blends and composites based on cellulose and natural polymers. In Biodegradable Polymer Blends and Composites from Renewable Resources; Long, Y., Ed.; John Wiley \& Sons, Inc.: Hoboken, NJ, USA, 2009; pp. 129-161. ISBN 9780470146835.

4. Sionkowska, A. Current research on the blends of natural and synthetic polymers as new biomaterials: Review. Prog. Polym. Sci. 2011, 36, 1254-1276. [CrossRef]

5. Duarte, A.P.; Coelho, J.F.; Bordado, J.C.; Cidade, M.T.; Gil, M.H. Surgical adhesives: Systematic review of the main types and development forecast. Prog. Polym. Sci. 2012, 37, 1031-1050. [CrossRef]

6. Santos, J.M.C.; Marques, D.S.; Alves, P.; Correia, T.R.; Correia, I.J.; Baptista, C.M.S.G.; Ferreira, P. Synthesis, functionalization and characterization of UV-curable lactic acid based oligomers to be used as surgical adhesives. React. Funct. Polym. J. 2015, 94, 43-54. [CrossRef]

7. Lasprilla, A.J.R.; Martinez, G.A.R.; Lunelli, B.H.; Jardini, A.L.; Filho, R.M. Poly-lactic acid synthesis for application in biomedical devices-A review. Biotechnol. Adv. 2012, 30, 321-328. [CrossRef] [PubMed]

8. Singhvi, M.S.; Zinjarde, S.S.; Gokhale, D.V. Polylactic acid: Synthesis and biomedical applications. J. Appl. Microbiol. 2019, 127, 1612-1626. [CrossRef]

9. Broz, M.E.; VanderHart, D.L.; Washburn, N.R. Structure and mechanical properties of poly(D,L-lactic acid)/poly(E-caprolactone) blends. Biomaterials 2003, 24, 4181-4190. [CrossRef]

10. Saini, P.; Arora, M.; Kumar, M.N.V.R. Poly(lactic acid) blends in biomedical applications. Adv. Drug Deliv. Rev. 2016, 107, 47-59. [CrossRef]

11. Mulinti, P.; Brooks, J.E.; Lervick, B.; Pullan, J.E.; Brooks, A.E. 10-Strategies to improve the hemocompatibility of biodegradable biomaterials. In Hemocompatibility of Biomaterials for Clinical Applications; Woodhead Publishing: Cambridge, UK, 2018; pp. 253-278.

12. Albertsson, A.C.; Varma, I.K. Aliphatic polyesters: Synthesis, properties and applications. Degrad. Aliphatic Polyesters 2002, 157, 1-40.

13. Williams, C.G.; Malik, A.N.; Kim, T.K.; Manson, P.N.; Elisseeff, J.H. Variable cytocompatibility of six cell lines with photoinitiators used for polymerizing hydrogels and cell encapsulation. Biomaterials 2005, 26, 1211-1218. [CrossRef] [PubMed]

14. Miguel, S.P.; Cabral, C.S.D.; Moreira, A.F.; Correia, I.J. Production and characterization of a novel asymmetric 3D printed construct aimed for skin tissue regeneration. Colloids Surf. B Biointerfaces 2019, 181, 994-1003. [CrossRef] [PubMed] 
15. Figueira, D.R.; Miguel, S.P.; de Sá, K.D.; Correia, I.J. Production and characterization of polycaprolactonehyaluronic acid/chitosan- zein electrospun bilayer nanofibrous membrane for tissue regeneration. Int. J. Biol. Macromol. 2016, 93, 1100-1110. [CrossRef] [PubMed]

16. Miguel, S.P.; Simões, D.; Moreira, A.F.; Sequeira, R.S.; Correia, I.J. Production and characterization of electrospun silk fibroin based asymmetric membranes for wound dressing applications. Int. J. Biol. Macromol. 2019, 121, 524-535. [CrossRef]

17. Cernadas, T.; Morgado, S.; Alves, P.; Gonçalves, F.A.M.M.; Correia, T.R.; Correia, I.J.; Ferreira, P. Preparation of functionalized poly(caprolactone diol)/castor oils blends to be applied as photocrosslinkable tissue adhesives. J. Appl. Polym. Sci. 2020,1-14. [CrossRef]

18. Cernadas, T.; Santos, M.; Gonçalves, F.A.M.M.; Alves, P.; Correia, T.R.; Correia, I.J.; Ferreira, P. Functionalized polyester-based materials as UV curable adhesives. Eur. Polym. J. 2019, 120, 109196. [CrossRef]

19. Lee, S.-Y.; Wu, S.-C.; Chen, H.; Tsai, L.-L.; Tzeng, J.-J.; Lin, C.-H.; Lin, Y.-M. Synthesis and Characterization of Polycaprolactone-Based Polyurethanes for the Fabrication of Elastic Guided Bone Regeneration Membrane. Biomed Res. Int. 2018, 2018, 1-13. [CrossRef] [PubMed]

20. Alves, P.; Santos, M.; Mendes, S.; Miguel, S.P.; de Sá, K.D.; Cabral, C.S.D.; Correia, I.J.; Ferreira, P. Photocrosslinkable nanofibrous asymmetric membrane designed for wound dressing. Polymers 2019, 11, 653. [CrossRef]

21. Travassos, D.R.S.; Santos, J.M.C.; Baptista, C.M.S.G.; Marques, D.S.; Ferreira, P.; Gil, M.H.; Ribeiro, M.P.; Correia, I.J.; Miguel, S.P. Engineering star-shaped lactic acid oligomers to develop novel functional adhesives. J. Mater. Res. 2018, 33, 1463-1474.

22. Proikakis, C.S.; Mamouzelos, N.J.; Tarantili, P.A.; Andreopoulos, A.G. Swelling and hydrolytic degradation of poly(d,1-lactic acid) in aqueous solutions. Polym. Degrad. Stab. 2006, 91, 614-619. [CrossRef]

23. Malik, M.; Kaur, R. Mechanical and thermal properties of castor oil-based polyurethane adhesive: Effect of $\mathrm{TiO}_{2}$ filler. Adv. Polym. Technol. 2018, 37, 21637. [CrossRef]

24. Valero, M.F.; Ortegón, Y. Polyurethane elastomers-based modified castor oil and poly( $\varepsilon$-caprolactone) for surface-coating applications: Synthesis, characterization, and in vitro degradation. J. Elastomers Plast. 2013, 47, 360-369. [CrossRef]

25. Sabnis, A.; Rahimi, M.; Chapman, C.; Nguyen, K.T. Cytocompatibility studies of an in situ photopolymerized thermoresponsive hydrogel nanoparticle system using human aortic smooth muscle cells. J. Biomed. Mater. Res. A 2009, 91, 52-59. [CrossRef] [PubMed]

26. Simões, D.; Miguel, S.P.; Ribeiro, M.P.; Coutinho, P.; Mendonça, A.G.; Correia, I.J. Recent advances on antimicrobial wound dressing: A review. Eur. J. Pharm. Biopharm. 2018, 127, 130-141. [CrossRef]

27. Miguel, S.P.; Ribeiro, M.P.; Coutinho, P.; Correia, I.J. Electrospun polycaprolactone/Aloe Vera_chitosan nanofibrous asymmetric membranes aimed for wound healing applications. Polymers 2017, 9, 183. [CrossRef]

28. Lyu, J.S.; Lee, J.S.; Han, J. Development of a biodegradable polycaprolactone film incorporated with an antimicrobial agent via an extrusion process. Sci. Rep. 2019, 9, 1-11. [CrossRef]

29. Zheng, J.; Li, L.; Tsao, H.K.; Sheng, Y.J.; Chen, S.; Jiang, S. Strong repulsive forces between protein and oligo (ethylene glycol) self-assembled monolayers: A molecular simulation study. Biophys. J. 2005, 89, 158-166. [CrossRef]

30. Yuan, Y.; Hays, M.P.; Hardwidge, P.R.; Kim, J. Surface characteristics influencing bacterial adhesion to polymeric substrates. RSC Adv. 2017, 7, 14254-14261. [CrossRef]

31. Wang, C.; Chang, T.; Yang, H.; Cui, M. Antibacterial mechanism of lactic acid on physiological and morphological properties of Salmonella Enteritidis, Escherichia coli and Listeria monocytogenes. Food Control 2015, 47, 231-236. [CrossRef]

32. Ray, B.; Daeschel, M. Food Biopreservatives of Microbial Origin, 1st ed.; CRC Press: Boca Raton, FL, USA, 2017.

Publisher's Note: MDPI stays neutral with regard to jurisdictional claims in published maps and institutional affiliations. 